\title{
Intermittent Hemodialysis for Patients With Acute Kidney Injury (AKI): Outcome in A Tertiary Level Hospital
}

\author{
Arun Sharma, Binod Karki and Ajay Rajbhandari
}

Department of Medicine, Nepalese Army Institute of Health Sciences, Shree Birendra Hospital, Chhauni, Kathmandu, Nepal.

\begin{abstract}
Introduction: Acute kidney injury (AKI) is the abrupt loss of kidney function, resulting in the retention of urea and other nitrogenous waste products and in the dysregulation of extracellular volume and electrolytes. In developing countries, community acquired AKI is common than AKI in hospitalized septic patients. Most patients with AKI recover renal function conservatively yet few require renal support with intermittent Hemodialysis (HD). We conducted a study in a tertiary level hospital to find out the etiology and outcome of the patients presenting with AKI who required dialysis.

Methods: This is a descriptive follow up study of the patients who needed renal replacement therapy in the form of HD presenting to our Nephrology unit of the hospital from Jan 2015 to Dec 2016, i.e. over a period of two years. Consent was taken from both the institution as well as the patients for the evaluation of data. Patients were followed up for at least three months from the time of enrolment. Data were tabulated and analysed using SPSS software.

Results: Total 50 patients were included in the study, out of which $67 \%$ were male. The mean age of the patients was 54.54 years $(\mathrm{SD} \pm 18.6)$. Hypertension was present in $44 \%$ and Diabetes in $18 \%$ as comorbidities. The commonest etiologies were urinary tract infection (30\%), acute gastroenteritis (24\%) and obstructive uropathy (18\%). The mean creatinine level at the time of nephrology consultation, maximum level and at the time of discharge were $6.5(\mathrm{SD} \pm 2.62), 7.3(\mathrm{SD} \pm 2.13)$ and $2.2(\mathrm{SD} \pm 1.75)$ respectively. Uremia with anuria was the most common reason for the initiation of HD $54 \%$ cases. The mean number of intermittent HD used was 3.36. Out of total patients, $68 \%$ had complete recovery, $26 \%$ died and $6 \%$ had persistent renal dysfunction at the end of three months.

Conclusions: UTI followed by acute gastroenteritis are the leading cause of AKI in our tertiary level hospital. Timely initiated renal replacement therapy in the form of intermittent HD could lead to substantial renal recovery in almost three fourth of patients.
\end{abstract}

Key words: Acute kidney injury; hemodialysis; outcome

Correspondence: Arun Sharma, Department of Medicine, Nepalese Army Institute of Health Sciences, Shree Birendra Hospital, Chhauni, Kathmandu, Nepal. Email: doctor_sharma2@yahoo.com

DOI: http://dx.doi.org/10.3126/mjsbh.v17i1.18629

Submitted on: $2017-11-22$

Accepted on: 2018-01-27 


\section{INTRODUCTION}

Acute kidney injury (AKI) is a common disorder worldwide, occurring in more than 13 million people every year, $85 \%$ of whom live in developing countries. ${ }^{1}$ The KDIGO (Kidney Disease: Improving Global Outcome) guidelines define AKI as increase in serum creatinine by $\geq 0.3 \mathrm{mg} /$ $\mathrm{dL}(\geq 26.5 \mathrm{micromol} / \mathrm{L})$ within 48 hours, or increase in serum creatinine to $\geq 1.5$ times baseline, which is known or presumed to have occurred within the prior seven days, or urine volume $<0.5 \mathrm{~mL} / \mathrm{kg} /$ hour for six hours. $^{2}$

In developed countries the cause of AKI is primarily hospital based where as in developing countries the cause is mainly community acquired. ${ }^{3,4}$ Renal replacement therapy in the form of intermittent hemodialysis is often instituted for volume overload resistant to diuretic agents, sudden hyperkalemia, severe metabolic acidosis, and uremic manifestations, including encephalopathy, pericarditis, and convulsion. It is unclear whether the early initiation of renal replacement therapy improves survival and renal recovery rates. 5,6

Nepal is one of the developing countries with limited medical resources facilities with acute gastroenteritis as a leading cause of AKI with almost 34\% requiring renal support in the form of dialysis. ${ }^{7}$ There are however very limited data on the spectrum of patients with AKI who needed dialysis and their outcome in the long term.

We conducted the study in a tertiary level hospital to find out the etiology of the AKI patients who needed the dialysis support and the outcome during hospital stay and long term follow up after hospital discharge.

\section{METHODS}

This is a descriptive follow up study conducted in a tertiary level referral hospital of Nepal. The study period was of two years from Jan 2015 to Dec 2016. All the patients who presented with AKI and those who needed renal support were included. Patients' clinical profile and lab parameters were recorded. Intermittent hemodialysis was offered to all the patients and the numbers of sessions were determined using the serial renal function parameters, urinary output. Patients with AKI recovering without dialysis and chronic kidney disease (CKD) patients were excluded. The patients once clinically improved and creatinine started resolving with adequate urine output were discharged. The patients were followed up till three months with serial renal function tests. Consent was taken from both the institution as well as the patients for the evaluation of data. Data were tabulated and analyzed as intention to treat basis using SPSS software and appropriate statistical tests.

\section{RESULTS}

Total 50 patients were included in the study, out of which $67 \%$ were male and with the mean age of 54.54 years $(\mathrm{SD} \pm 18.6)$. The details of other baseline characteristics is shown in Table 1. The commonest etiologies were urinary tract infection $(30 \%)$ followed by acute gastroenteritis (24\%) and other causes as shown in the figure 1. Among the miscellaneous etiology, two patients had AKI due to complicated falciparum malaria who had

Table 1: Baseline characteristics of the patients

\begin{tabular}{|l|r|r|}
\hline \multicolumn{1}{|c|}{ Parameters } & \multicolumn{1}{c}{ Mean } & \multicolumn{1}{c|}{ SD \pm} \\
\hline Age & 54.54 & 18.16 \\
\hline Male & $64 \%$ & \\
\hline Hypertension & $44 \%$ & \\
\hline Diabetes & $18 \%$ & \\
\hline Se creatinine & $6.5 \mathrm{mg} / \mathrm{dl}$ & 2.6 \\
\hline WBC & $10,784 / \mathrm{cc}$ & 3130 \\
\hline Hb & $12.15 \mathrm{mg} / \mathrm{dl}$ & 1.68 \\
\hline
\end{tabular}




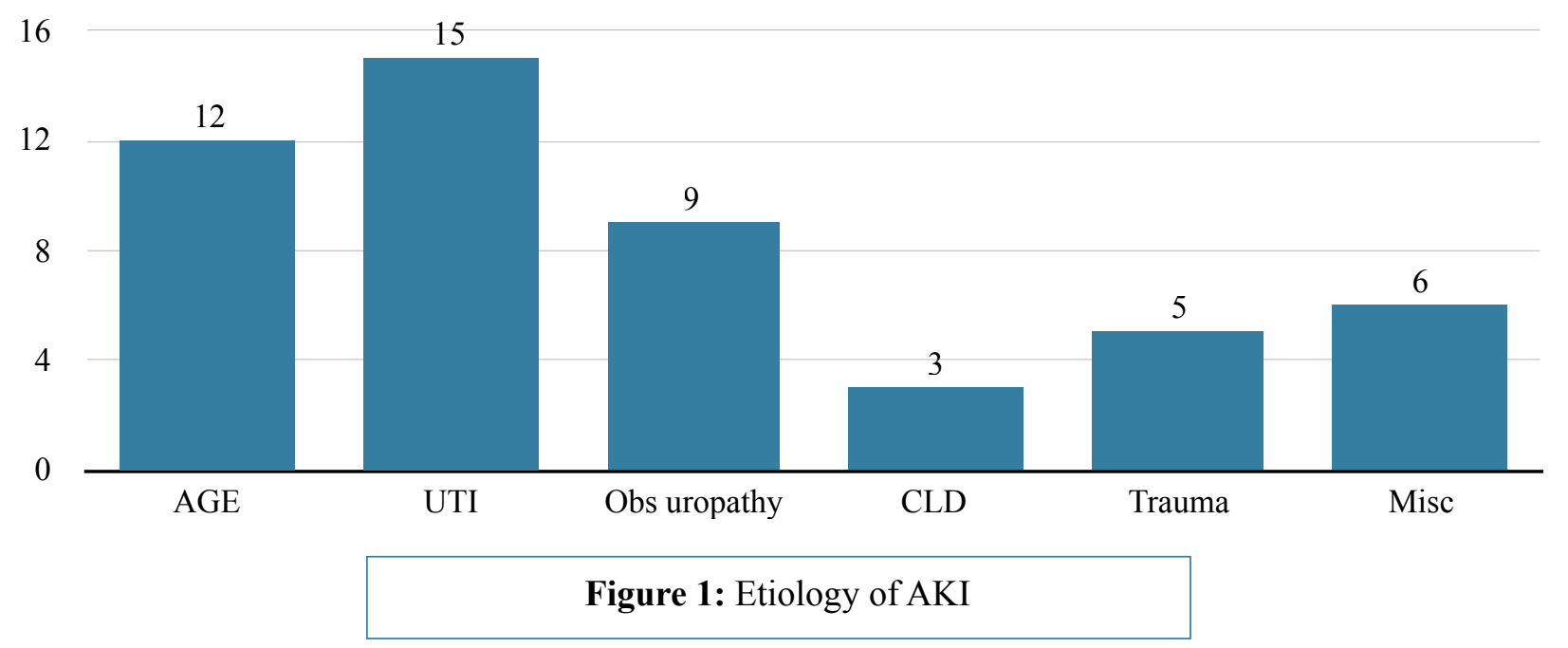

returned recently from Sudan after serving United Nation missions and two had rhabdomyolysis due to heat stroke sustained during training in Terai. All the four patients had normal recovery post dialysis and during follow up for three months.

The mean creatinine level at the time of nephrology consultation, maximum level and at the time of discharge were $6.5(\mathrm{SD} \pm 2.62), 7.3(\mathrm{SD} \pm 2.13)$ and $2.2(\mathrm{SD} \pm 1.75)$ respectively. The commonest reason for starting the dialysis was uremia with anuria in $54 \%$ cases followed by anuria alone in $28 \%$ cases and rest because of hyperkalemia, uremia alone or severe acidosis. Intermittent hemodialysis was provided as per the requirement and the minimum number of session was one and the maximum was six; the mean number of dialysis session was $3.36 \pm 1.12$. No serious complications were observed during dialysis sessions. The mean length of hospital stay was $15.9 \% \pm 8.9$ days and was not affected by the number of dialysis session $(p=0.40)$. There were $13(26 \%)$ deaths altogether as shown in figure 2, mainly in the group having urinary tract infections and chronic liver disease. There was no significant association between age, etiology or the maximum serum creatinine and the clinical outcome. At the time of discharge from the hospital, $50 \%$ have creatinine below $1.5 \mathrm{mg} / \mathrm{dl}$ and at the end of three months except for three patients who continued to have deranged renal function hence labeled as CKD; all those who survived had normal creatinine level.

\section{DISCUSSION}

Acute renal failure is a common diagnosis in hospital settings and development or progression of chronic kidney disease after one or more episode of acute kidney injury could have striking socioeconomic and public health outcomes for all countries. ${ }^{1}$ In our study, the commonest cause of AKI was UTI followed by acute gastroenteritis which was in consistent with study done by Chhetri PK et al. ${ }^{7}$, where out of 45 patients, the etiologies were acute gastroenteritis 33, sepsis five,

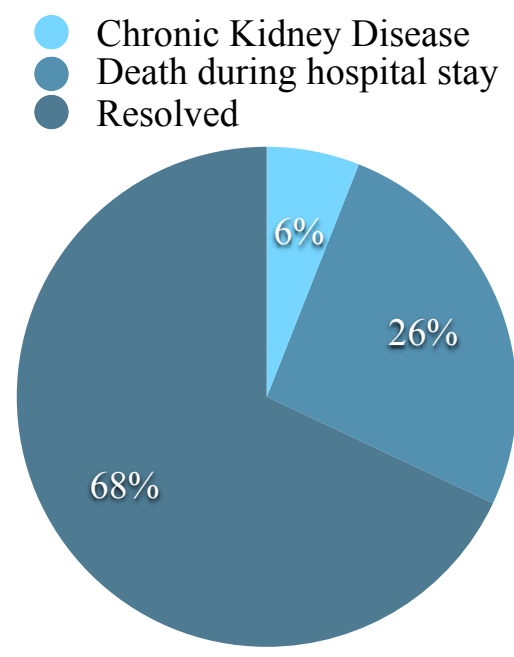

Figure 2: Outcome of patients at 3 months 
hemorrhage two, others five were the different causes of AKI. Urinary tract infection and other infections leading to sepsis are leading cause of AKI mainly in hospitalized setting in developed countries as opposed to community acquired infections like enteric infections leading to hypovolemia in developing countries. ${ }^{8}$ In our study, UTI was leading cause which reflects the increasing number of critical care patients admitted as a referral care hospital. This was also reflected in a study done by Prakash J et al. ${ }^{9}$ where they have analyzed 2405 cases in 26 years from Eastern India and found the decreasing number of acute gastroenteritis and other infections as causes of $\mathrm{AKI}$ and increasing number of in hospital sepsis.

Among the other etiologies, we have four interesting cases as AKI which were not described in other studies from Nepal. ${ }^{7}$ There were two cases of complicated falciparum malaria leading to AKI in personnel returning from Sudan recently. Koopmans LC et al. ${ }^{10}$ has showed that up to $8 \%$ of AKI were due to imported falciparum malaria. The pathogenesis of AKI in malaria is still not clearly understood. Blockage of renal microcirculation due to sequestration of infected erythrocytes, immune-mediated glomerular injury and volume depletion are some of the proposed hypotheses. ${ }^{11}$ Another two cases were related to rhabdomyolysis associated AKI secondary to heat stroke in our recruitment training centre. This is uncommon in other hospital and has been described as case reports only. 12

The mean creatinine level at the time of nephrology consultation and the initiation of dialysis were similar to the other study done in Nepal.7,13 The commonest reason for starting the dialysis was uremia with anuria in $54 \%$ cases. The absolute indications for starting renal replacement which are well validated are hyperkalemia and overt uremic symptoms however the optimal timing of therapy in patients without these indications continues to be the subject of debate. There does not appear to be a difference in either mortality or recovery of kidney function associated with the various modalities of renal support. ${ }^{14}$

While analyzing the outcomes in our study, 26\% death occurred all together in all AKI patients and mainly in those having UTI with sepsis, chronic liver disease and trauma related AKI. In a study done by Ghimire $\mathrm{M}$ et $\mathrm{al} .{ }^{15}, 47.1 \%$ case expired among patients with sepsis related AKI and there was $8 \%$ mortality among AKI patients as shown by Chhetri PK et al. ${ }^{7}$ In our study the level of creatinine was not significantly associated with the mortality and other outcomes unlike shown in one study where patients who had presented with increment in serum level of creatinine of $\geq 101 \%$ with respect to basal values, at the time of nephrology consultation, had increased mortality rates and were discharged from hospital with a more deteriorated renal function. ${ }^{16}$

At the time of discharge, almost half of the patients had normal renal function and at the end of three months follow up, only three $(6 \%)$ had persistent renal dysfunction thus diagnosed as CKD. There are no Nepalese studies on long term follow up of AKI patients; however it was comparable to the study done by Ali $\mathrm{T}$ et al. ${ }^{17}$ where the incidence of CKD after AKI was $6.5 \%$.

\section{CONCLUSIONS}

UTI followed by acute gastroenteritis are the leading cause of AKI in our tertiary level hospital. After timely initiation of intermittent hemodialysis, we could salvage almost $74 \%$ patients with normal renal functions in most of them at the end of three months follow up. 
To cite this article: Sharma A, Karki B, Rajbhandari A. Intermittent Hemodialysis For Patients With Acute Kidney Injury (AKI): Outcome In A Tertiary Level Hospital. MJSBH. 2018;17(1):25-30.

Conflict of Interest: None declared

\section{REFERENCES}

1. NH, Bagga A, Cruz D, et al. Acute kidney injury: an increasing global concern. Lancet. 2013;382(9887): $170-9$

DOI: https://doi.org/10.1016/s0140-6736(13)60647-9

2. KDIGO Clinical Practice Guideline for Acute Kidney Injury. Kidney Int Suppl 2012; 2:8. KDIGO Clinical Practice Guideline for Acute Kidney Injury. Kidney Int Suppl 2012; 2:8.

3. Jha V, Parameswaran S. Community-acquired acute kidney injury in tropical countries. Nat Rev Nephrol. 2013;9(5):278-290.

DOI: https://doi.org/10.1038/nrneph.2013.36

4. Chertow GM, Burdick E, Honour M, Bonventre JV, Bates DW. Acute kidney injury, mortality, length of stay, and costs in hospitalized patients. J Am Soc Nephrol. 2005;16(11):3365-70.

DOI: https://doi.org/10.1681/asn.2004090740

5. Sugahara S, Suzuki H. Early start on continuous hemodialysis therapy improves survival rate in patients with acute renal failure following coronary bypass surgery. Hemodial Int. 2004;8:320-25.

DOI: https://doi.org/10.1111/j.1492-7535.2004.80404.x

6. Bagshaw SM, Uchino S, Bellomo R, Morimatsu H, Morgera S, Schetz M, et al. Timing of renal replacement therapy and clinical outcomes in critically ill patients with severe acute kidney injury. J Crit Care. 2009;24:129-40.

DOI: https://doi.org/10.1016/j.jcrc.2007.12.017

7. Chhetri PK, Manandhar DN, Pahari LR, Chhetri SS, Chaudhary SK. Acute renal failure in Nepal Medical College Teaching Hospital. Nepal Med Coll J. 2008;10(2):132-5.

PMID: 18828439

8. Cerdá J, Bagga A, Kher V, Chakravarthi RM. The contrasting characteristics of acute kidney injury in developed and developing countries. Nat Clin Pract Nephrol. 2008 Mar;4(3):138-53.

DOI: $10.1038 /$ ncpneph0722

9. Prakash J, Singh TB, Ghosh B, Malhotra v, Rathore SS, Vohra R. Changing epidemiology of community-acquired acute kidney injury in developing countries:analysis of 2405 cases in 26 years from eastern India. Clinical Kidney Journal. 2013;6(2):150-5.

DOI:10.1093/ckj/sfs178.

10. Koopmans LC, Wolfswinkel ME, Hesselink DA, Hoorn EJ, Koelewijn R, Hellemond Van JJ et al. Acute kidney injury in imported Plasmodium falciparum malaria.Malaria Journal. 2015;14:523 
DOI: https://doi.org/10.1186/s12936-015-1057-9

11. Mishra SK, Das BS. Malaria and acute kidney injury. Semin Nephrol. 2008;4:395-408.

DOI: http://dx.doi.org/10.1016/j.semnephrol.2008.04.007

12. Trujillo MH, Fragachán GC. Rhabdomyolysis and Acute Kidney Injury due to Severe Heat Stroke.Case reports in Critical Care. 2011;2-3

DOI:10.1155/2011/951719

13. Khakurel S, Satyal PR, Agrawal RK, Chhetri PK, Hada R. Acute renal failure in a tertiary care center in Nepal. JNMA J Nepal Med Assoc. 2005;44(158):32-5.

PMID: 16554867

14. Palevsky PM.Renal Replacement Therapy in AKI. Advances in chronic kidney disease. 2013;20(1): 76-84.

DOI:10.1053/j.ackd.2012.09.004.

15. Ghimire M, Pahari B, Sharma SK, Thapa L, Das G, Das GC. Outcome of sepsis-associated acute kidney injury in an intensive care unit: an experience from a tertiary care center of central Nepal.Saudi J Kidney Dis Transpl. 2014 Jul;25(4):912-7.

DOI: https://doi.org/10.4103/1319-2442.135229

16. Perez-Valdivieso JR, Bes-Rastrollo M, Monedero P, de Irala J, Lavilla FJ.Prognosis and serum creatinine levels in acute renal failure at the time of nephrology consultation: an observational cohort study. BMC Nephrology. 2007;8:14.

DOI:10.1186/1471-2369-8-14.

17. Ali T, Khan I, Simpson W, Prescott G, Townend J, Smith W et al. Incidence and Outcomes in Acute Kidney Injury: A Comprehensive Population-Based Study. JASN. 2007;18(4):1292-8.

DOI: 10.1681/ASN.2006070756 